\title{
Hidroelektrik Santrallerde Vardiya Çizelgeleme Problemleri İçin Hedef Programlama Yaklaşımı
}

\author{
Evren Can ÖZCAN ${ }^{1}$, Emre VARLI ${ }^{2}$, Tamer EREN $^{3}$ \\ ${ }^{1}$ Bakım Yönetim Sistemi Müdürlüğü, Elektrik Üretim A.Ş. Genel Müdürlüğü, Ankara, Türkiye \\ ${ }^{2}$ Endüstri Mühendisliği Bölümü, Kırıkkale Üniversitesi, Kırıkkale, Türkiye \\ ${ }^{3}$ Endüstri Mühendisliği Bölümü, Kırıkkale Üniversitesi, Kırıkkale, Türkiye \\ enmcan@gmail.com, ef.varli@gmail.com, teren@kku.edu.tr \\ (Geliş/Received:05.01.2017; Kabul/Accepted:27.09.2017) \\ DOI: 10.17671/gazibtd.347609
}

\begin{abstract}
$\ddot{O}_{z} \boldsymbol{e t}$ - Kuruluṣların hitap ettikleri kitleleri en üst seviyede memnun etmeleri, kâr ve sistem verimi maksimizasyonu ile maliyet minimizasyonu gibi üst ölçekteki hedeflere ulaşmaları birçok parametre üzerinde yoğunlaşmalarını gerekli kılmaktadır. Ürün ve hizmet üretiminde istihdam edilen personelin söz konusu hedeflere ulaşılmasındaki önemli etkisi dikkate alındığında, çalışanlar arasında adil iş dağılımının sağlanması ile çalışanların yeterlilik, istek ve ihtiyaçlarına uygun nitelikteki işlerde, güvenlik içinde çalışmasını temin ederek motivasyon ve performanslarının artırılmasına hizmet eden personel çizelgelemenin önemi ortaya çıkmaktadır. Bu bağlamda bu çalışma kapsamında, çalışan performansının artırılmasına odaklanmış, adil çalışma ve işin gerekliliklerini birlikte dikkate alan bir hedef programlama modeli önerilmiş ve çalışan performansının önemli sonuçlar doğuracağı Türkiye'deki büyük ölçekli bir hidroelektrik santraldeki gerçek veriler kullanılarak modelin çözümü neticesinde, modelin kullanılmadığı döneme göre operatör hatasından kaynaklı üretim duruşlarında \%91'lik iyileşme sağlandığı tespit edilmiştir.
\end{abstract}

Anahtar Kelimeler — vardiya personeli çizelgeleme, hidroelektrik santral, elektrik üretimi, hedef programlama

\section{Goal Programming Approach for Shift Scheduling Problems in Hydroelectric Power Plants}

\begin{abstract}
The organizations are required to focus on many parameters to please the population they address at the maximum level and accomplish their high-level goals such as profit and system efficiency maximization and cost minimization. Taking the important impact of the staff employed for product and service production in reaching the mentioned goals, the importance of personnel scheduling occurs which serves to increase their motivation and performance providing fair division of tasks and providing the employees to work in the appropriate qualities as per competence, desire and needs in safety. Within this context in this this study, a goal programming model which focuses on increasing the performance of the employees and considering the fair working conditions and work requirements jointly, is proposed and, as a result of the model solution using the real data in a big scale hydroelectric power plant in Turkey where the employee performance leads to important results, it is determined that there is an improvement about $91 \%$ in downtimes arise from operator faults compared to the period when the model is not used.
\end{abstract}

Keywords - shift employee scheduling, hydroelectric power plant, electricity generation, goal programming

\section{GİRIŞ (INTRODUCTION)}

Hizmet ya da üretim sektöründe yer alan kamu ve özel sektör kuruluşlarının tamamı için kâr maksimizasyonu, maliyet minimizasyonu, sistem veriminin maksimizasyonu, müşteri memnuniyetinin mümkün olan en üst düzeye çıkarılması gibi ortak hedeflerden bahsedilebilir. $\mathrm{Bu}$ tip makro hedeflere ulaşmak için birçok parametrenin ayrı ayrı ya da eş zamanlı olarak iyileştirilmesi gerekli olmakla birlikte, kuruluşların hizmet ve/veya ürün üretiminde kullandıkları ana kaynakların başında gelen istihdam ettikleri çalışanlarının performansı temel belirleyici etkenlerdendir. Bu kapsamda, genellikle çözümü zor optimizasyon problemleri arasında yer alan ve çeşitli hizmetlerin yerine getirilmesi için her bir çalışanın yeterlilikleri, ihtiyaçları ve istekleri doğrultusunda hizmetlerin niteliğini de dikkate alacak şekilde kullanılabilir çalışma planlarının oluşturulması olarak tanımlanabilecek personel çizelgelemenin kullanımı 
kuruluşlara çalışan performansının artırılması açısından firsatlar sunmaktadir [1].

Elektrik üretim santrallerinde üretimin gerçekleştirilmesi ve gerekli bakım - onarım faaliyetlerinin yürütülmesi kompleks yapılı, uzmanlık gerektiren ve emek yoğun faaliyetler olarak karşımıza çıkmaktadır. $\mathrm{Bu}$ tesislerin çıktısı olan elektrik enerjisinin insan yaşamı üzerindeki yüksek etkisi ve vazgeçilmezliği dikkate alındığında, işe uygun çalışanların atanması ve çalışan performansının iyileştirilmesinin, santrallere sağlayacağı parasal katma değerin yanında toplum üzerindeki etkisi daha da ön plana çıkmaktadır. $\mathrm{Bu}$ bağlamda bu çalışma kapsamında, çalışanların nitelikleri ile yapılacak işlerin gereklilikleri birlikte dikkate alınarak hem üretim sürecinin hem de çalışan performansının artırılması amacıyla çalışanlar arasında adil iş dağılımı yapılması için bir hedef programlama modeli önerilmiş ve gerçek veriler kullanılarak bu modelin çözümü Türkiye'de yer alan büyük ölçekli bir hidroelektrik santralde gerçekleştirilmiştir.

Çalışmanın ikinci bölümünde hidroelektrik santrallerin işletme esasları, Türkiye açısından önemi ve bu tesislerde personel çizelgelemenin önemi özetlenmiş, üçüncü ve dördüncü bölümlerde sırasıyla hedef programlama tanıtılarak literatürde yapılan çalışmalardan bahsedilmiştir. Beşinci bölümde, önerilen model sunulmuş ve son bölümde ise modelin çözümünden elde edilen sonuçlar yorumlanarak ileride yapılabilecek çalışmalar ile ilgili tavsiyelerde bulunulmuştur.

\section{HIDROELEKTRIK SANTRALLER VE ISSLETME ESASLARI (HYDROELECTRIC POWER PLANTS AND OPERATING RULES)}

Elektrik enerjisi üretiminde yenilenebilir kaynak kullanımı dünya genelinde sürekli olarak artış göstermektedir. Dünyada yenilenebilir enerji kaynakları arasında kurulu güç açısından ilk sırada ise hidrolik yer almaktadır [2]. Uluslararası Enerji Ajansının tahminlerine göre 2040'a kadar olan süreçte, $\% 6,9$ 'luk oran ile yenilenebilir kaynaklar en hizlı büyüme oranına sahip enerji kaynakları olacaktır. $\mathrm{Bu}$ kapsamda, sadece hidrolik gücün yıllık ortalama $\% 1,8$ büyüme oranına sahip olması beklenmektedir [3].

Hidrolik güç, baz yük elektrik ihtiyacını karşılayabilmesinin yanı sıra, puant ve beklenmeyen güç taleplerini karşılayabilmesi açısından da en tutarlı ve en esnek yenilenebilir enerji kaynağıdır. Türkiye, yıllık 140 milyar kWh'lik hidrolik potansiyeli ve dünya genelinde hidrolik güç kullanımı açısından 7. sıradaki yeri ile bu önemli kaynak açısından fakir olmayan bir ülkedir [2]. 2016 Ekim ayı sonu itibariyle 78.434 MW kurulu güce sahip olan Türkiye'de, \%33,7'lik oran ile hidroelektrik santraller ilk sirada yer almaktadır. Yine 2016 Ekim ayı sonu itibariyle Türkiye'de üretilen 225,6 milyar kWh'lik elektrik üretiminin \%25,5'i hidroelektrik santrallerden karşılanmıştır [3]. Bu verilere göre, Türkiye elektrik üretim sektörü açısından hidroelektrik santraller büyük öneme sahiptir ve bu nedenle bu çalışmada, uygulama sahası olarak hidroelektrik santraller seçilmiştir.

Hidroelektrik santraller, su tutma ve su alma yapısı, iletim kanalı ya da tüneli (cebri borular gibi), salyangoz, türbin-generator sistemi, trafolar ve şalt ekipmanlarından oluşan büyük ölçekli sürekli üretim tesisleridir. Bu santraller, günümüzün sürekli gelişen teknolojisi ile santral sahasına dağıtılmış kontrol sistemlerine (DCS) bağlı SCADA sistemleri ile uzaktan ya da bir ana kontrol merkezinden işletme (vardiya) personeli tarafindan kumanda edilerek, santralın üretim planına ve/veya otorite kuruluşların verdiği talimatlara göre devreye alınır, çalışma yükü artırılır ya da kapasitesinin daha altındaki yüklerde çalıştırılabilir. Bu tesislerin ekonomik ömürleri, yapılan rehabilitasyonlar sonucunda onlarca y1l uzat1labilmektedir. Buradan hareketle, tüm dünyada olduğu gibi Türkiye'de de SCADA sistemine sahip olmamasına rağmen halen işletmede olan santraller mevcuttur. Bu hidroelektrik santraller ise, otomasyon seviyesi gelişmiş SCADA sistemlerine göre çok daha düşük olan ana kumanda merkezlerinden ve santral sahasinda yer alan ekipmanlara mahallinden müdahale edilmek suretiyle çalıştırılmaktadır. Günümüz teknolojisine nazaran daha eski teknolojiye sahip bu santrallerde çalışan vardiya personelinin sayısı doğal olarak modern hidroelektrik santrallere göre daha fazladır ve bu santraller vardiya personelinden kaynaklanan operatör hatalarına daha müsaittir. Başka bir deyişle SCADA sistemi, gelişmiş yapısı sayesinde santralde insanın etkisini azaltırken, SCADA sistemi olmayan santrallerde vardiya personelinin konsantrasyon eksikliği, yoğun çalışma sonucunda yaşayacağı yorgunluk, tecrübe yetersizliği ve adil çalışma düzeninin olmaması sonucunda motivasyon kaybı yaşaması gibi nedenlerden dolayı hatalı işlemler yaşanabilmekte ve bu durumlar sonucunda uzun süren arızalar ve buna bağlı olarak da milyonlarca kWh enerji ve gelir kaybı yaşanabilmektedir.

$\mathrm{Bu}$ kapsamda, özellikle günümüzün gelişmiş teknolojisine sahip olmayan hidroelektrik santrallerin işletilmesinde görevli vardiya personelinin yeterliliklerine göre adil bir plan dahilinde çalıştırılmasının, santralı uhdesinde bulunduran şirkete sağladığı ekonomik değeri önemli ölçüde etkilediği şeklindeki bir yorum yanlış olmayacaktır. 


\section{HEDEF PROGRAMLAMA (GOAL PROGRAMMING)}

Günlük ya da iş yaşantısında insanlar, birbirleri ile çelişen ya da ilişkili kriterlere bağlı olarak sürekli kararlar almak durumunda kalmaktadır [4]. Çalışmanın da konusunu teşkil eden elektrik üretiminde personel çizelgeleme gibi uygulandıkları sisteme büyük ölçüde katma değer sağlaması beklenen kritik kararların verilmesi sürecinde, analitik yaklaşımların kullanılması kararların etkinliği açısından son derece önemlidir. Bu bağlamda, bu analitik yaklaşımlar bütününden birisi olan hedef programlama etkin karar vermede sıklıkla kullanılagelmektedir. Hedef programlamanın genel amacı, değerleri kesin olarak belirlenen birden fazla amacın, hedef değerlerinden sapmalarını minimize etmektir. Hedef programlamanın matematiksel gösterimi şu şekilde verilebilir [5].

Minimize $Z=\sum_{i=1}^{k}\left(d_{i}^{-}+d_{i}^{+}\right)$

$\sum_{j=1}^{n} a_{i j} x_{j}+d_{i}^{-}-d_{i}^{+}=b_{i}$

$x_{j}, d_{i}^{-}, d_{i}^{+} \geq 0 \quad i=1 \ldots k \quad j=1 \ldots n$

Değişkenler

$x_{j}: j$. karar değişkeni

$a_{i j}: i$. hedefin $j$. karar değişkeni katsayısı

$b_{i}: i$. hedef için ulaşılmak istenen değer

$d_{i}^{+}: i$. hedefin pozitif sapma değişkeni

$d_{i}^{-}: i$. hedefin negatif sapma değişkeni

\section{LITERATÜR ARAŞTIRMASI (LITERATURE REVIEW)}

Personel çizelgeleme problemleri ile ilgili ilk çalışmalar 1954 yılında Edie [6] ve Dantzing [7] tarafından yapılmıştır. Daha sonraki yıllarda yapılan çalışmaların büyük bir çoğunluğunun sağlık sektöründe yoğunlaştığı söylenebilir. Fakat diğer sektörlerde de farklı çalışma kuralları kullanılarak çalışmalar da bulunmaktadır. Jorne ve arkadaşlarının belirttiği üzere [8], enerji sektöründe çalışan personellerin çalışma planlarının yapılması konusunda literatürde fazla sayıda çalışma bulunmamaktadır $\mathrm{Bu}$ kapsamda, sektörel bazda literatürde yapılan bazı çalışmalara ait örnekler şöyledir:

Să̆llk Sektörü: Ovchinnikov ve Milner [9], bir üniversite hastanesinde çalışan stajyer doktorlar için hastanenin belirlediği işgücünü karşılama adına bir model geliştirmişlerdir. Bag vd. [10], bir devlet hastanesinde çalışan hemşirelerin aylık çalışma planlarının yapılması için bir model sunmuşlardır. Li vd. [11] ise, hedef programlama ve sezgisel hibrit yöntem yaklaşımı ile hemşirelerin çalışma planının düzenlenmesi konusunda bir çalışma yapmışlardır. Ismail vd. [12], hemşire çizelgeleme problemi üzerinde çalışmışlar ve geliştirdikleri modeli Malezya'daki bir hastanede uygulamışlardır. Topaloğlu [13], stajyer olarak çalışan doktorları kıdem seviyeleriyle birlikte değerlendirerek bir çizelge oluşturmuştur. Sulak ve Bayhan da [14], hemşire çizelgeleme problemi için bir çalışma gerçekleştirmişlerdir.

Ulaşım Sektörü: Varli vd. [15], Ankara metro hattında çalışan ekiplerin belirli bir zaman diliminde gerekli iş gücünün karşılanması için bir çalışma yapmışlardır. Ankara şehir içi faaliyette olan metro hattındaki vatmanların günlük belirlenmiş olan vardiyalara iş yerinin belirlediği kriterler dikkate alınarak bir çalışma planının oluşturulduğu diğer bir çalışma ise, Varli vd. [16] tarafindan gerçekleştirilmiştir. Alfares [17], çalışan personellerin izin günleri için farklı kısıtlamalar kullanarak bir model oluşturmuştur. Avusturalya'da taşımacılık yapan kamyon sürücülerinin çalışma çizelgelerini planlamasına yönelik çalışmalarında Goel vd. [18], önerdikleri modeli Avusturalya Ağır Vasıta Sürücü Yorgunluk Kanununu baz alarak hazırlamışlardır.

Enerji Sektörü: Eitzen vd. [19], bir elektrik üretim santralında birçok alanda beceriye sahip olan personellerin uzmanlaştıkları iş kollarına atanması için bir çalışma gerçekleştirmişlerdir. Lilly vd. [20] çalışmalarında, Nijerya'da hizmet veren bir elektrik üretim şirketinde bakım işlemlerinin yapılabilmesi için bakım iş gücü giderlerinin minimum seviyeye indirilmesi amacıyla bir model önermişlerdir. Yaoyuenyong ve Nanthavani [21], gerekli iş gücünü karşılamak için en az işçiyle çalışmak adına bir çizelge oluşturmuşlardır.

Askeri Alan: Ünal ve Eren [22] çalışmalarında, nöbet çizelgeleme problemi konusunda bir model önermişlerdir. Horn vd. [23], Avusturalya Kraliyet Donanmasında çalışan personeller için sezgisel yöntemlerden faydalanarak bir model oluşturmuşlardır.

Diğer Alanlar: Gordon ve Erkut [24], bir halk müziği festivalinde gönüllü çalışan personellere zaman kazandırmak için bir çalışma planı oluşturmuşlardır. Bard [25], gelen taleplere göre işçi hacmini dengelemek için bir çalışma gerçekleştirmiştir. Avramidi vd. [26] ise, simülasyon yöntemini kullanarak çağrı merkezindeki personellerin çizelgelenmesi üzerine bir çalışma gerçekleştirmişlerdir. Heimerl ve Kolisch [27], 
önerdikleri tam sayılı programlama modeli ile işçi ücretlerini minimize etmeyi amaçlamışlardır. Hojati ve Patil [28], tam sayılı programlama yöntemiyle vardiyaların belirlenmesi ve personellerin vardiyalara atanması konusunda bir çalışma gerçekleştirmişlerdir. Varli ve Eren [29], bir fabrikada çalışan şeflerin aylık çalışma planlarının yapılması için bir hedef programlama modeli önermişlerdir. Modeli oluştururken şefleri kıdemlerine göre sınıflandırmışlar ve tecrübeli şef ile tecrübesiz şefin aynı vardiyaya mümkün olduğu kadar atanmasını sağlamışlardır. Volgenant [30], personelleri kıdem konusunda sınıflandırarak ihtiyaç duyulan işgücünün karşılanmasını amaçlamıştır. Bektur ve Hasgül [31] ise, hedef programlama yöntemini kullanarak bir restoranda çalışan personelin haftalık çalışma çizelgesini oluşturmuştur.

\section{UYGULAMA (CASE STUDY)}

Türkiye'de SCADA sistemine sahip olmayan 90 MW kurulu güce (hidroelektrik santrallerin sınıflandırılmasında $10 \mathrm{MW}$ ve üzeri kurulu güçler büyük ölçekli hidroelektrik santral grubuna girmektedir) sahip büyük ölçekli bir hidroelektrik santralde, personel performansina etki eden temel unsurların ikinci bölümde belirtilen nedenler olduğu gözlemlenmiş ve uzun yıllar ortalamaları incelenerek santralın en yoğun çalıştığı ayların Haziran, Temmuz ve Ağustos olduğu tespit edilmiştir. Söz konusu aylarda 2016 yılında yaşanan ve vardiya personelinin hatasından kaynaklanan üretim kayıpları da (Haziran ve Temmuz ayları için 44'er saat) dikkate alınarak, 28 vardiya personeli için adil çalışma düzenini ve mümkün olan en üst seviyede performansı üretecekleri bir hedef programlama modeli önerilerek, aynı yılın Ağustos ayında söz konusu modelin çözümü neticesinde oluşturulan çizelgeye göre vardiya personeli çalıştırılmıştır. $\mathrm{Bu}$ çizelgenin çalışanlar üzerinde motivasyon ve performans bazlı etkileri çalışmamızın sonuç bölümünde vurgulanmıştır.

\subsection{Modelin Ön Şartları (Preconditions of the Model)}

Çalışmada önerilen model, uygulamanın gerçekleştirildiği hidroelektrik santralin belirlediği kanuni ve özel şartlara dayanarak hazırlanmıştır:

- Her personel günde sekiz saatten fazla çalışmamalıdır.

- Her vardiyada yedi personel olması gerekmektedir.

- Her personel ardışık olarak en fazla altı gün çalışmalıdır ve altı günün sonunda izin verilmelidir.

- Her vardiyada en az bir tane 1. kidemden, en az iki tane 2. kidemden, en az bir tane 3. kidemden ve en az bir tane 4 . kıdemden personel olmak zorundadır.
- Aylık çizelgede her personelin toplam atandıkları vardiya sayıları kıdem seviyelerine göre azalmalıdır. Örneğin 1. kıdemde olan bir personel, diğer kıdemlerde olan personellerden daha az vardiyaya atanmalıdır.

- Her personel çalıştığı vardiyadan sonra bir sonraki çalışacağı vardiyaya atanana kadar en az 12 saat dinlenmelidir.

- Bunların yanı sıra, personelin çalıştığ 1 vardiyaların arasında geçen tatil süresinin mümkün olduğunca azaltılması istenmektedir. Bunun nedeni, kritik ve kompleks olan elektrik üretim sürecinde sürekliliği sağlayarak personelin konsantrasyonunu yüksek tutmak ve bu sayede hataları minimize etmektir.

Yukarıda belirtilen ön şartlar ile birlikte santraldeki 28 vardiya personelinin yeterlilikleri ve santralın işletilmesi için gereklilikler dikkate alınarak adil, dengeli ve personelin performansindan en üst seviyede istifade etmeyi sağlamak amaciyla önerilen model aşağıda sunulmuştur.

\subsection{Matematiksel Model (Mathematical Model)}

Y1lın 365 günü 24 saat esasına göre kesintisiz üretim yapma hedefi ile kurulan elektrik üretim santrallerinde sekizer saatlik üç vardiya vardır. Çalışmanın gerçekleştirildiği hidroelektrik santralde bu vardiyalar; Sabah (08:00-16:00), Akşam (16:00-00:00), Gece (00:00-08:00) şeklindedir. Santralde çalışan personelin kıdem seviyeleri Tablo 1'de verilmiştir.

Tablo 1. Santralde çalışan personellerin kıdemleri (Seniorities of the personnel employed in power plant)

\begin{tabular}{|c|c|}
\hline Kıdem Seviyeleri & Personeller \\
\hline 1.K1dem & $1,2,3,4,5$ \\
\hline 2.K1dem & $6,7,8,9,10,11,12,13,14$ \\
\hline 3.K1dem & $15,16,17,18,19,20,21,22$ \\
\hline 4.K1dem & $23,24,25,26,27,28$ \\
\hline
\end{tabular}

\section{Parametreler}

n: Santralde çalışan personel sayısı $\quad n=28$

$m$ : Ağustos ayındaki gün sayısı $\quad m=31$

$t$ : Vardiya sayısı $\quad t=3$

$i$ : Santralde çalışan personel indeksi, $\quad i=1,2, \ldots, n$.

$j$ : Gün indeksi, $\quad j=1,2, \ldots, m$.

$k$ : Vardiya indeksi $\quad k=1,2, \ldots, t$.

Karar Değişkenleri

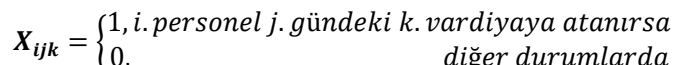

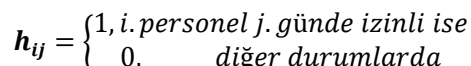

Kisitlar

1.Kısıt: Her gün, her vardiya için ihtiyaç duyulan personel sayıları. 
$\sum_{i=1}^{n} X_{i j k}=7$

$$
j=1,2, \ldots, m k=1,2, \ldots, t
$$

2.K1sit: Her vardiyada k1demlerine göre atanan personel sayıları.

1.kıdeme sahip personellerden her vardiyada en az bir tane olması gerekmektedir.

$$
\begin{aligned}
X_{(1) j k}+X_{(2) j k}+X_{(3) j k}+X_{(4) j k}+X_{(5) j k} & \geq 1 \\
j=1,2, \ldots, m k & =1,2, \ldots, t
\end{aligned}
$$

2.kıdeme sahip personellerden her vardiyada en az iki tane olması gerekmektedir.

$X_{(6) j k}+X_{(7) j k}+X_{(8) j k}+X_{(9) j k}+X_{(10) j k}+X_{(11) j k}+$ $X_{(12) j k}+X_{(13) j k}+X_{(14) j k} \geq 2 \quad j=1,2, \ldots, m$ $k=1,2, \ldots, t$

3.kıdeme sahip personellerden her vardiyada en az iki tane olması gerekmektedir.

$X_{(15) j k}+X_{(16) j k}+X_{(17) j k}+X_{(18) j k}+X_{(19) j k}+$

$X_{(20) j k}+X_{(21) j k}+X_{(22) j k} \geq 2 \quad j=1,2, \ldots, m$

$k=1,2, \ldots, t$

4.kıdeme sahip personellerden her vardiyada en az bir tane olması gerekmektedir.

$X_{(23) j k}+X_{(24) j k}+X_{(25) j k}+X_{(26) j k}+X_{(27) j k}+$

$X_{(28) j k} \geq 1 \quad j=1,2, \ldots, m k=1,2, \ldots, t$

3.K1sıt: Herhangi bir gün gece vardiyasında çalışan bir personel ertesi gün sabah ve akşam vardiyalarında çalışmamalıdır.

$X_{i j 3}+X_{i(j+1) 1}+X_{i(j+1) 2} \leq 1 \quad i=1,2, \ldots, n$ $j=1,2, \ldots, m$

4.Kısıt: Herhangi bir gün akşam vardiyasında çalışan bir personel ertesi gün sabah vardiyasında çalışmamalıdır.

$$
\begin{gathered}
X_{i j 2}+X_{i(j+1) 1} \leq 1 \quad i=1,2, \ldots, n \\
j=1,2, \ldots, m
\end{gathered}
$$

5.Kısıt: Her personel altı günden fazla art arda çalışmamalıdır.

$h_{i j}+h_{i(j+1)}+h_{i(j+2)}+h_{i(j+3)}+h_{i(j+4)}+h_{i(j+5)}+$

$h_{i(j+6)} \geq 1 \quad i=1,2, \ldots, n \quad j=1,2, \ldots, m-6$

6.Kısıt: Her personel izinli olduğu gün çalışmamalıdır.

$\sum_{k=1}^{l} X_{i j k} \leq\left(1-h_{i j}\right) \quad i=1,2, \ldots, n j=1,2, \ldots, m$

7.Kısıt: Her personelin planlama yapılan toplam gün boyunca en fazla çalışması gereken vardiya sayıları

1., 2. ve 3. k1deme sahip personeller en fazla dokuz defa akşam vardiyasında çalışmalıdır.

$\sum_{j=1}^{m} X_{i j 2} \leq 9$

$i=1 . .22$

$\mathrm{Bu}$ k1sitlar, her personelin kıdem seviyesine göre en fazla çalışması gereken gece vardiyası sayıları içindir.

$\sum_{j=1}^{m} X_{i j 3} \leq 7$

$i=1 . .5$

$\sum_{j=1}^{m} X_{i j 3} \leq 8$

$i=6 . .14$

$\sum_{j=1}^{m} X_{i j 3} \leq 9$

$i=15 . .22$ $\sum_{j=1}^{m} X_{i j 3} \leq 10$

$i=23 . .28$

8.K1sit: Her personelin planlama yapılan toplam gün boyunca en az çalışması gereken vardiya sayıları

Sabah ve akşam vardiyalarında her personel en az altı defa çalışmalıdır.

$\sum_{j=1}^{m} X_{i j k} \geq 6 \quad i=1,2, \ldots, n \quad k=1,2$

$\mathrm{Bu}$ kısıtlar, her personelin kıdem seviyesine göre en az çalışması gereken gece vardiyası sayıları içindir.

$\sum_{j=1}^{m} X_{i j 3} \geq 6$

$i=1 . .5$

$\sum_{j=1}^{m} X_{i j 3} \geq 7$

$i=6 . .14$

$\sum_{j=1}^{m} X_{i j 3} \geq 8$

$i=15 . .22$

$\sum_{j=1}^{m} X_{i j 3} \geq 9$

9.Kısıt: Her personel günde sadece bir vardiya atanmalidir.

$$
\begin{gathered}
\sum_{k=1}^{l} X_{i j k} \leq 1 \quad i=1,2, \ldots, n \quad j=1,2, \ldots, m \\
k=1,2, \ldots, t
\end{gathered}
$$

\section{Hedef Kisitlarl}

Hedef 1: Her personelin kıdemine göre toplam atandığ vardiyalar mümkün olduğu kadarıyla eşit olmalıdır.

1. kıdeme sahip personeller

$\sum_{j=1}^{m} \sum_{k=1}^{t} X_{i j k}+n 1_{i}^{-}-n 1_{i}^{+}=22 \quad \mathrm{i}=1,2,3,4,5$

2. k1deme sahip personeller

$\sum_{j=1}^{m} \sum_{k=1}^{t} X_{i j k}+n 2_{i}^{-}-n 2_{i}^{+}=23$

$\mathrm{i}=6,7,8,9,10,11,12,13,14$

3. k1deme sahip personeller

$\sum_{j=1}^{m} \sum_{k=1}^{t} X_{i j k}+n 3_{i}^{-}-n 3_{i}^{+}=23$

$\mathrm{i}=15,16,17,18,19,20,21,22$

4. k1deme sahip personeller

$\sum_{j=1}^{m} \sum_{k=1}^{t} X_{i j k}+n 4_{i}^{-}-n 4_{i}^{+}=25$ $\mathrm{i}=23,24,25,26,27,28$

Hedef 2: Her personel için çalışma-tatil-çalışma günleri en aza indirgenmelidir.

$h_{i j}+X_{i(j+1) 1}+X_{i(j+1) 2}+X_{i(j+1) 3}+h_{i(j+2)}+n 5_{i j}^{-}-$ $n 5_{i j}^{+}=2 \quad i=1,2, \ldots, 28 \quad j=1,2, \ldots, 29$

Hedef 3: Her personel için tatil-çalışma-tatil günleri en aza indirgenmelidir.

$X_{i j 1}+X_{i j 2}+X_{i j 3}+h_{i(j+1)}+X_{i(j+2) 1}+X_{i(j+2) 2}+$

$X_{i(j+2) 3}+n 6_{i j}^{-}-n 6_{i j}^{+}=2 \quad i=1,2, \ldots, 28 j=1,2, \ldots, 29$

2. ve 3. hedef kısıtları kuruluşun belirlediği ön şartlar arasinda belirtilen hedefi yansitmaktadir.

Amaç Fonksiyonu: $\operatorname{MinZ}=\sum_{j=1}^{m} n 1_{j}^{-}+n 1_{j}^{+}+$ $n 2_{j}^{-}+n 2_{j}^{+}+n 3_{j}^{-}+n 3_{j}^{+}+n 4_{j}^{-}+n 4_{j}^{+}+$ $\sum_{i=1}^{n} \sum_{j=1}^{m} n 5_{i j}^{-}+n 5_{i j}^{+}+n 6_{i j}^{-}+n 6_{i j}^{+}$

Önerilen model, ILOG CPLEX Studio IDE programında yazılmış ve CPLEX çözücüsü ile 
çözülerek elde edilen sonuçlar Tablo 2'de gösterilmiştir.

Tablo 2. Santralde çalışan personellerin Ağustos 2016 vardiya çizelgesi

(August 2016 shift schedule of the personnel employed in power plant)

\begin{tabular}{|c|c|c|c|c|c|c|c|c|c|c|c|c|c|c|c|c|c|c|c|c|c|c|c|c|c|c|c|c|c|c|c|c|c|c|c|}
\hline & 1 & 2 & 3 & 4 & 5 & 6 & 7 & 8 & 9 & 10 & 11 & 12 & 13 & 14 & 15 & 16 & 17 & 18 & 19 & 20 & 21 & 22 & 23 & 24 & 25 & 26 & 27 & 28 & 29 & 30 & 31 & $S$ & A & G & TOPLAM \\
\hline 1 & $S$ & S & $\mathrm{A}$ & A & & A & $\mathrm{A}$ & A & $\mathrm{G}$ & & $S$ & $\mathrm{G}$ & & $S$ & $\mathrm{~A}$ & & & \begin{tabular}{|l|}
$S$ \\
\end{tabular} & $S$ & $S$ & $\mathrm{~A}$ & $\mathrm{G}$ & & & $S$ & $S$ & & & $\mathrm{G}$ & $\mathrm{G}$ & $\mathrm{G}$ & 9 & 7 & 6 & 22 \\
\hline 2 & A & & S & S & A & G & G & $\mathrm{G}$ & & $S$ & G & & S & $S$ & \begin{tabular}{|l|} 
\\
\end{tabular} & A & A & A & & A & G & & $S$ & G & & & $S$ & $S$ & $S$ & & & 10 & 6 & 6 & 22 \\
\hline 3 & G & $G$ & & & & S & $\mathrm{S}$ & & & & $S$ & $S$ & $\mathrm{G}$ & $\mathrm{G}$ & & $\mathrm{G}$ & $\mathrm{G}$ & & $S$ & $S$ & $S$ & $\mathrm{~A}$ & $\mathrm{~A}$ & $\mathrm{~A}$ & & $S$ & $S$ & $\mathrm{~A}$ & $\mathrm{~A}$ & $\mathrm{~A}$ & $\mathrm{~A}$ & 9 & 7 & 6 & 22 \\
\hline 4 & & & G & $\mathrm{G}$ & G & & & S & \begin{tabular}{|l|}
$\mathrm{A}$ \\
\end{tabular} & $\mathrm{A}$ & $\mathrm{A}$ & $\mathrm{A}$ & $\mathrm{A}$ & & & $S$ & $\mathrm{~S}$ & $\begin{array}{ll} \\
\end{array}$ & $\mathrm{A}$ & & $S$ & \begin{tabular}{|l|}
$S$ \\
\end{tabular} & $\mathrm{G}$ & & G & $\mathrm{G}$ & $G$ & & $S$ & $S$ & $S$ & 9 & 6 & 7 & 22 \\
\hline 5 & $S$ & A & & $S$ & $S$ & S & S & & S & G & & & $S$ & A & G & & $S$ & G & G & $\mathrm{G}$ & & & & $S$ & A & A & A & $\mathrm{G}$ & & $S$ & A & 10 & 6 & 6 & 22 \\
\hline 6 & $\mathrm{~S}$ & $S$ & \begin{tabular}{|l|} 
\\
\end{tabular} & $S$ & $S$ & & $\mathrm{~A}$ & $\mathrm{~A}$ & & $\mathrm{~A}$ & $\mathrm{~A}$ & & & $\mathrm{~A}$ & \begin{tabular}{|l|l|} 
\\
\end{tabular} & $\mathrm{G}$ & $\mathrm{G}$ & & & $S$ & $S$ & $\mathrm{~A}$ & $\mathrm{G}$ & $G$ & & $S$ & $G$ & $\mathrm{G}$ & & S & $\mathrm{G}$ & 9 & 7 & 7 & 23 \\
\hline 7 & $S$ & & & A & $\mathrm{A}$ & G & $\mathrm{G}$ & $\mathrm{G}$ & $\mathrm{G}$ & & $S$ & $S$ & $\mathrm{~A}$ & $\mathrm{~A}$ & $\mathrm{G}$ & & $S$ & S & $S$ & A & $\mathrm{A}$ & & & $\mathrm{G}$ & $\mathrm{G}$ & $G$ & & $\mathrm{~A}$ & A & $\mathrm{A}$ & & 6 & 9 & 8 & 23 \\
\hline 8 & $\mathrm{~A}$ & & S & $S$ & $\mathrm{G}$ & G & & $\mathrm{A}$ & $\mathrm{A}$ & $G$ & $\mathrm{G}$ & $\mathrm{G}$ & & $S$ & \begin{tabular}{|l|} 
\\
\end{tabular} & $S$ & & G & $\mathrm{G}$ & & $S$ & $\mathrm{~A}$ & & $\mathrm{~A}$ & $\mathrm{~A}$ & $\mathrm{~A}$ & $\mathrm{~A}$ & & $\mathrm{~A}$ & $\mathrm{G}$ & & 6 & 9 & 8 & 23 \\
\hline 9 & $\mathrm{~A}$ & G & $\mathrm{G}$ & & S & S & S & $S$ & $\mathrm{~A}$ & $\mathrm{~A}$ & & & & & \begin{tabular}{|l|}
$S$ \\
\end{tabular} & $\mathrm{G}$ & & $\mathrm{A}$ & $\mathrm{A}$ & $\mathrm{G}$ & $\mathrm{G}$ & G & $G$ & & S & $S$ & & $S$ & $S$ & A & $\mathrm{A}$ & 9 & 7 & 7 & 23 \\
\hline 10 & G & $G$ & G & & G & G & & $S$ & $S$ & $S$ & & $S$ & $S$ & $S$ & $\mathrm{~A}$ & $\mathrm{~A}$ & $\mathrm{~A}$ & & $\mathrm{~A}$ & $\mathrm{~A}$ & $\mathrm{~A}$ & & $\mathrm{~A}$ & $\mathrm{~A}$ & & $\mathrm{~A}$ & $G$ & $\mathrm{G}$ & $\mathrm{G}$ & & & 6 & 9 & 8 & 23 \\
\hline 11 & G & & $\mathrm{A}$ & $\mathrm{A}$ & $\mathrm{A}$ & A & $\mathrm{A}$ & $\mathrm{G}$ & & & $S$ & $S$ & $\mathrm{~S}$ & & \begin{tabular}{|l|}
$S$ \\
\end{tabular} & $S$ & $\mathrm{~S}$ & & & 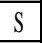 & $\mathrm{A}$ & G & & $\mathrm{S}$ & $\mathrm{G}$ & & $S$ & $S$ & $\mathrm{G}$ & $\mathrm{G}$ & $G$ & 10 & 6 & 7 & 23 \\
\hline 12 & & $\mathrm{~S}$ & S & $\mathrm{G}$ & & A & $\mathrm{G}$ & & S & $S$ & $\mathrm{~A}$ & $\mathrm{~A}$ & $\mathrm{~A}$ & $\mathrm{~A}$ & & $\mathrm{G}$ & $\mathrm{G}$ & G & $\mathrm{G}$ & & & S & $\mathrm{S}$ & $S$ & S & $G$ & & & S & $\mathrm{A}$ & A & 9 & 7 & 7 & 23 \\
\hline 13 & $\mathrm{~A}$ & A & $\mathrm{A}$ & $\mathrm{G}$ & & & S & $\mathrm{G}$ & $\mathrm{G}$ & & & $\mathrm{A}$ & $\mathrm{G}$ & $\mathrm{G}$ & & $\mathrm{A}$ & $\mathrm{A}$ & $\mathrm{A}$ & $\mathrm{G}$ & $\mathrm{G}$ & $\mathrm{G}$ & & $S$ & $\mathrm{~S}$ & $S$ & & $S$ & $\mathrm{~A}$ & $\mathrm{~A}$ & & $\mathrm{~S}$ & 6 & 9 & 8 & 23 \\
\hline 14 & & A & $\mathrm{A}$ & $\mathrm{G}$ & & S & S & $\mathrm{A}$ & & $G$ & $G$ & $\mathrm{G}$ & $\begin{array}{ll} \\
\end{array}$ & $\mathrm{G}$ & G & & & S & \begin{tabular}{l|} 
\\
\end{tabular} & A & & S & A & $\mathrm{A}$ & $\mathrm{A}$ & $\mathrm{A}$ & A & & & $S$ & $S$ & 7 & \begin{tabular}{l|l}
9 \\
\end{tabular} & 7 & 23 \\
\hline 15 & 3 & S & $\mathrm{A}$ & $\mathrm{A}$ & A & A & & & $\mathrm{A}$ & $\mathrm{A}$ & $\mathrm{A}$ & $\mathrm{G}$ & $\mathrm{G}$ & & \begin{tabular}{|l|}
$S$ \\
\end{tabular} & $\mathrm{~S}$ & $\mathrm{G}$ & $\mathrm{G}$ & & $\mathrm{G}$ & $\mathrm{G}$ & G & & & $\mathrm{S}$ & S & $\mathrm{A}$ & $\mathrm{A}$ & & & $\mathrm{G}$ & 6 & \begin{tabular}{l|}
9 \\
\end{tabular} & 8 & 23 \\
\hline 16 & $\mathrm{~A}$ & A & & & S & A & A & & $S$ & $S$ & & $\mathrm{~A}$ & $\mathrm{G}$ & $\mathrm{G}$ & & $S$ & S & $\mathrm{G}$ & $G$ & & $S$ & S & $S$ & $\mathrm{G}$ & $\mathrm{G}$ & & $\mathrm{A}$ & $\mathrm{A}$ & $\mathrm{G}$ & $\mathrm{G}$ & & 8 & 7 & 8 & 23 \\
\hline 17 & G & & & $\mathrm{A}$ & A & A & & $S$ & $S$ & $S$ & & & $\mathrm{~A}$ & $\mathrm{~A}$ & \begin{tabular}{l|l|} 
\\
\end{tabular} & $\mathrm{A}$ & $\mathrm{G}$ & G & & 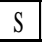 & $\mathrm{A}$ & G & $\mathrm{G}$ & $G$ & & S & G & $\mathrm{G}$ & $\mathrm{G}$ & & $\mathrm{S}$ & 6 & 8 & 9 & 23 \\
\hline 18 & $\mathrm{~A}$ & A & & $S$ & G & & $\begin{array}{ll}G \\
\end{array}$ & $\mathrm{G}$ & & $S$ & $S$ & $S$ & $S$ & $\begin{array}{l}\mathrm{G} \\
\end{array}$ & & $\mathrm{A}$ & $\mathrm{A}$ & $\mathrm{A}$ & $\mathrm{A}$ & & $\mathrm{A}$ & $\mathrm{A}$ & $\mathrm{A}$ & & G & G & G & $\mathrm{G}$ & & & $\mathrm{S}$ & 6 & 9 & 8 & 23 \\
\hline 19 & S & $\mathrm{G}$ & G & & $\mathrm{A}$ & G & $\mathrm{G}$ & & $S$ & $\mathrm{~A}$ & $\mathrm{~A}$ & $\mathrm{~A}$ & $\mathrm{G}$ & & \begin{tabular}{|l|}
$S$ \\
\end{tabular} & $\mathrm{G}$ & & S & $S$ & 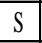 & $S$ & $\mathrm{~S}$ & & & $\mathrm{~A}$ & G & & $S$ & $\mathrm{~A}$ & $\mathrm{G}$ & & 9 & 6 & 8 & 23 \\
\hline 20 & G & G & G & $\mathrm{G}$ & & & $\mathrm{A}$ & $\mathrm{A}$ & $\mathrm{G}$ & $\mathrm{G}$ & $G$ & & & $S$ & G & & $\mathrm{A}$ & $\mathrm{A}$ & $\mathrm{A}$ & $\mathrm{A}$ & & S & $S$ & $S$ & $\mathrm{~A}$ & A & & & $S$ & S & $\mathrm{S}$ & 7 & 8 & 8 & 23 \\
\hline 21 & G & & & $S$ & S & S & S & $S$ & $\mathrm{~A}$ & & $S$ & $\mathrm{~A}$ & $\mathrm{~A}$ & $\mathrm{~A}$ & G & & $\mathrm{S}$ & $\mathrm{A}$ & & & & G & $\mathrm{G}$ & $G$ & & G & $\mathrm{G}$ & & $\mathrm{A}$ & $\mathrm{A}$ & $\mathrm{A}$ & 7 & 8 & 8 & 23 \\
\hline 22 & & S & S & A & G & & & $S$ & G & G & G & G & & $S$ & A & G & & $S$ & A & $\mathrm{G}$ & & A & A & A & & & $S$ & $S$ & $S$ & A & G & 8 & 7 & 8 & 23 \\
\hline 23 & $\mathrm{~A}$ & $\mathrm{~A}$ & $\mathrm{~A}$ & & S & $\mathrm{S}$ & $\mathrm{G}$ & $\mathrm{G}$ & $\mathrm{G}$ & $G$ & & $S$ & $S$ & $S$ & A & $\mathrm{A}$ & $\mathrm{A}$ & & & $S$ & $\mathrm{~A}$ & $\mathrm{~A}$ & $\mathrm{G}$ & $G$ & $\mathrm{G}$ & & $\mathrm{A}$ & $\mathrm{A}$ & $\mathrm{G}$ & $\mathrm{G}$ & & 6 & 10 & 9 & 25 \\
\hline 24 & G & G & G & & G & $\mathrm{G}$ & $\mathrm{G}$ & $\mathrm{G}$ & & & 0 & $\mathrm{~S}$ & $\mathrm{~A}$ & $\mathrm{~A}$ & $G$ & & $S$ & $S$ & $S$ & & $S$ & S & & $\mathrm{A}$ & $\mathrm{A}$ & $\mathrm{A}$ & & $\mathrm{A}$ & $\mathrm{A}$ & $\mathrm{A}$ & $\mathrm{G}$ & 7 & 9 & \begin{tabular}{|l|}
9 \\
\end{tabular} & 25 \\
\hline 25 & S & $S$ & S & $S$ & S & & A & $\mathrm{A}$ & $\mathrm{A}$ & $\mathrm{A}$ & $\mathrm{A}$ & $\mathrm{G}$ & & & A & $\mathrm{A}$ & $\mathrm{G}$ & & $\mathrm{G}$ & $\mathrm{G}$ & $\mathrm{G}$ & $\mathrm{G}$ & $\mathrm{G}$ & & $S$ & A & $\mathrm{A}$ & $\mathrm{G}$ & $\mathrm{G}$ & & $\mathrm{A}$ & 6 & 10 & 9 & 25 \\
\hline 26 & & $\mathrm{~S}$ & $S$ & $\mathrm{~A}$ & $\mathrm{~A}$ & A & $\mathrm{A}$ & & $S$ & $S$ & $\mathrm{~A}$ & $\mathrm{~A}$ & $\mathrm{~A}$ & $\mathrm{G}$ & & $\mathrm{S}$ & $\mathrm{A}$ & G & $\mathrm{G}$ & $\mathrm{G}$ & & & $S$ & $S$ & $\mathrm{~A}$ & G & G & $G$ & & $\mathrm{G}$ & $\mathrm{G}$ & 7 & 9 & 9 & 25 \\
\hline 27 & & $\mathrm{G}$ & G & G & & $S$ & $S$ & A & $\mathrm{A}$ & $\mathrm{A}$ & $\mathrm{G}$ & $S$ & & $\mathrm{G}$ & G & $\mathrm{G}$ & $\mathrm{G}$ & & $S$ & $\mathrm{~A}$ & & $\mathrm{~A}$ & $\mathrm{~A}$ & $\mathrm{~A}$ & $\mathrm{G}$ & & $\mathrm{S}$ & $S$ & 3 & $S$ & S & 9 & 7 & 9 & 25 \\
\hline 28 & & A & A & G & G & G & & $S$ & G & G & G & G & G & & $S$ & $S$ & & A & A & A & G & & $S$ & $S$ & $S$ & S & $S$ & $S$ & & S & A & 10 & 6 & 9 & 25 \\
\hline
\end{tabular}

Vardiyalar S: Sabah

\section{SONUÇLAR (RESULTS)}

Personel çizelgeleme, adil ve dengeli bir çalışma planı üretmesi ile çalışanların motivasyonunu artırması açısından personel performansına olumlu etkiler sağlayan yöneylem araştırmasında önemli bir çalışma alanıdır. Bunun yanı sıra, milyarlarca dolarlık yatırım bütçeleri ve karmaşık üretim ve bakım-onarım süreçleri ile birkaç saatlik duruşların dahi önemli ekonomik ve toplumsal etkiler doğuracağı elektrik üretim santrallerinde, çıktısı olan elektrik enerjisinin politik, sosyo-ekonomik ve diplomatik açıdan günümüzün vazgeçilmez tüketim noktalarından birisi olması gerçeği dikkate alındığında, kalifiye personellerin performans düzeylerinin sürekli olarak en üst düzeyde kalacak şekilde istihdam edilmeleri bir gereklilik halini almaktadır.

$\mathrm{Bu}$ bağlamda bu çalışmada, halihazırda Türkiye elektrik üretim sistemi içerisinde yer alan ve $90 \mathrm{MW}$ kurulu güce sahip olan bir hidroelektrik santralde,

\section{A: Akşam $\quad$ G: Gece}

santralın en yoğun çalıştığı Haziran, Temmuz ve Ağustos aylarında yorgunluk ve motivasyon eksikliğine bağlı olarak operatör hatası nedeniyle önemli arızaların yaşandığı tespit edilmiştir. 2016 yılında bu arızalardan kaynaklanan duruş süresi santralde Haziran ve Temmuz ayları için 44'er saattir. $\mathrm{Bu}$ duruşlar, $90 \mathrm{MW}$ kurulu güce sahip olan söz konusu hidroelektrik santralde 3,96 milyon $\mathrm{kWh}$ enerjinin her bir ay için üretilememesi anlamına gelmektedir ve bu enerji kaybının 2016 toptan elektrik satış fiyatı olan $14,87 \mathrm{kr} / \mathrm{kWh}$ 'lik [32] değer açısından karşılığı Haziran ve Temmuz ayları için ayrı ayrı olmak üzere 588.852 TL'dir.

Vardiya personelinin çalışma planının oluşturulmasında yapılan hatalara bağlı yaşanan kayıpların önüne geçilmesi için bu çalışmada, santral sahibi kuruluşun uyması gereken yasal zorunluluklar ve çalışma prensipleri dikkate alınarak her bir vardiya personeli için çalışma günlerini dengeleyecek kısıtlar oluşturulmuş ve personellerin Ağustos ayı çalışma 
planları, kıdem seviyelerine göre toplam vardiya atamalarının hiyerarşik bir şekilde olması, gece vardiyalarının kıdem seviyeleri ile orantılı bir şekilde dağıtılması, izin günlerinin düzenlenmesi ve her bir personelin dengeli ve adaletli bir şekilde vardiyalara atanması gibi iyileștirmeler gerçekleștiren ve bu çalışma kapsamında önerilen hedef programlama modelinin çözümü neticesinde elde edilmiştir. Ağustos ayında bu vardiya çizelgesinin kullanımı neticesinde ay sonu yapılan analizde operatör hatasına bağlı olarak yaşanan üretim duruşunun 4 saate indiği tespit edilmiştir. $\mathrm{Bu}$ da, \%91'lik bir iyileşmenin sağlandığg anlamına gelmektedir.

Elektrik üretim santrallerinde santralden kaynaklı duruşların beraberinde getirdiği önemli ekonomik kayıpların söz konusu olması, bu çalışmada personel çizelgelemesi sonucunda elde edilen tatminkar sonuçlar ve enerji sektöründe personel çizelgeleme probleminin nadiren kullanılması ile literatüre bu çalışmanın sağlayacağı katkıya dayanarak, ileri bir çalışma olarak hem vardiya personelleri hem de bakım-onarım personelleri birlikte değerlendirilerek yeni modeller önerilebilir. Ayrıca, bu çalışmada ele alınan çalışma alanı, personel niteliklerinin tamamının çok kriterli karar verme yöntemleri ya da istatistiksel yöntemler gibi analitik yöntemler ile farklı bakış açılarıyla da değerlendirilebilir.

\section{KAYNAKÇA (REFERENCES)}

[1] T. Ernst, H. Jiang, M. Krishnamoorthy, B. Owens, D. Sier, "An Annotated Bibliography of Personnel Scheduling and Rostering”, Annals of Operations Research, 127, 21- 144, 2004.

[2] REN 21, "Renewables 2015 Global Status Report", REN21 Renewable Energy Policy Network for the 21st Century, 2016.

[3] B. Albayrak, "2017 Yılı Bütçe Sunumu”, T.C. Enerji ve Tabii Kaynaklar Bakanlığı, 2016.

[4] E.C. Özcan, U. Küçükyarar, "Assessment of Potential Southern Gas Corridor Projects with a Combined Methodology", $\mathbf{2 3}^{\text {rd }}$ World Energy Congress, World Energy Council, İstanbul, 09-13 Ekim, 105-121, 2016.

[5] W.W. Charnes, "Goal Programming and Multiple Objective Optimizations", European Journal of Operational Research, $1,39-54,1977$.

[6] L. C. Edie, "Traffic Delays at Toll Booths", Operations Research, 2, 107-138, 1954.

[7] G. B. Dantzig, "Letter to the editor-A comment on Edie's "Traffic delays at toll booths". Operations Research, 2, 339$341,1954$.

[8] V.B. Jorne, B. Jeroen, D. B. Philippe, D. Erik, D. B. Liesje, "Personnel Scheduling: A Literature Review", Hub Research Papers 2012/43, Economics \& Management, 2012.

[9] Ovchinnikov, J. Milner, "Spreadsheet Model Helps to Assign Medical Residents at the University of Vermont's College of Medicine", Interfaces, 38, 311-323, 2008.
[10] N. Bağ, M. Özdemir, T. Eren, "0-1 Hedef programlama ve ANP Yöntemi ile Hemşire Çizelgeleme Problemi Çözümü”, International Journal of Engineering Research and Development, 4, 1, 2012.

[11] J. Li, E. K. Burke, T. Curtois, S. Petrovic, Q. Rong, "The Falling Tide Algorithm: A New Multi-Objective Approach for Complex Workforce Scheduling”, Omega, 40, 283-293, 2012.

[12] W.R. Ismail, R. Jenal, N.A. Hamdan, "Goal Programming Based Master Plan for Cyclical Nurse Scheduling”, Journal of Theoretical and Applied Information Technology, 46(1): 499504, 2012.

[13] S. Topaloglu, "A Shift Scheduling Model for Employees with Different Seniority Levels and an Application in Healthcare", European Journal of Operational Research, 198, 943-957, 2009.

[14] H. Sulak, M. Bayhan, "A Model Suggestion and an Application for Nurse Scheduling Problem", Journal of Research in Business, Economics and Management (JRBEM), 2395-2210, 2016.

[15] E. Varlı, T. Eren, M. A. Gençer, S. Cetin, "Ankara Metrosu M1 Hattındaki Vatmanların Vardiya Saatlerinin Çizelgelenmesi”, 3. Uluslararası Raylı Sistemler Mühendisliği Sempozyumu, Karabük, 279-285, 2016.

[16] E. Varli, M. A. Gençer, T. Eren, "Ankara Metro Hatları Vardiya Saatlerinin Çizelgelenmesi”, 9. Uluslararası İstanbul Ulaşım Kongresi ve Fuarı, 2016.

[17] H.K. Alfares, "Compressed Work Week Scheduling with Days off Consecutively, Weekend off Frequency, and Work stretch constraints", Infor, 44, 175-189, 2006.

[18] A. Goel, C. Archetti, M. Savelsbergh, "Truck Driver Scheduling in Australia", Computers \& Operations Research, 39, 1122-1132, 2012

[19] G. Eitzen, D. Panton, G. Mills, "Multi-Skilled Workforce Optimization", Annals of Operations Research, 127, 359-372, 2004.

[20] M.T. Lilly, I. Emovon, S.O.T. Ogaji, S.D. Probert, "Four-Day Service-Staff Workweek in order to Complete Maintenance Operations More Wffectively in a Nigerian Power Generating Station”, Applied Energy, 84, 1044-1055, 2007.

[21] K. Yaoyuenyong, S. Nanthavanij, "Energy-based Workforce Scheduling Problem: Mathematical model and Solution Algorithms", Science Asia, 31, 383-393, 2005.

[22] F.M. Ünal, T. Eren, "Hedef Programlama ile Nöbet Çizelgeleme Probleminin Çözümü”, Akademik Platform Mühendislik ve Fen Bilimleri Dergisi, 4(1): 28-37, 2016.

[23] M. Horn, H. Jiang, P. Kilby, "Scheduling Patrol Boats and Crews for the Royal Australian Navy", Journal of the Operational Research Society, 58, 1284-1293, 2007.

[24] L. Gordon, E. Erkut, "Improving Volunteer Scheduling for the Edmonton Folk Festival” Interfaces, 34, 367-376, 2004.

[25] J. F. Bard, "Selecting the Appropriate Input Data Set when Configuring a Permanent Workforce", Computers \& Industrial Engineering, 47, 371-389, 2004.

[26] N. Avramidis, W. Chan, M. Gendreau, P. L'Ecuyer, O. Pisacane, "Optimizing Daily Agent Scheduling in a Multi Skill Call Center", European Journal of Operational Research, 200, 822-832, 2010. 
[27] Heimerl, R. Kolisch, "Scheduling and Staffing Multiple Projects with a Multi-Skilled Workforce", OR Spectrum, 32, 343-368, 2010.

[28] M. Hojati, A. S. Patil, “An Integer Linear Programming-based Heuristic for Scheduling Heterogeneous, Part-time Service Employees", European Journal of Operational Research, 209, 37-50, 2011.

[31] G. Bektur, S. Hasgül, "Kıdem Seviyelerine Göre İşgücü Çizelgeleme Problemi: Hizmet Sektöründe Bir Uygulama", Afyon Kocatepe Üniversitesi, IIBF Dergisi, 15(2): 387-402, 2013.
[29] E. Varli, T. Eren, "Vardiya Cizelgeleme Problemi ve Bir Örnek Uygulama", International Journal of Informatics Technologies, 2016. (Basimda)

[30] A. Volgenant, "A Note on the Assignment Problem with Seniority and Job Priority Constraints", European Journal of Operational Research, 154, 330-335, 2004.

[32] Enerji Piyasası Düzenleme Kurumu (EPDK), “2016 Toptan Elektrik Satış Fiyatı”, 2016. 